EDUR • Educação em Revista. 2020; 36:e221449

DOI: http://dx.doi.org/10.1590/0102-4698221449

(9) (1) https://creativecommons.org/licenses/by/4.0/

ARTí́CULO

\title{
LA RESPONSABILIDAD PEDAGÓGICA ANTE LA EXPERIENCIA DEL LÍMITE EN LA INFANCIA: LA INTRODUCCIÓN A LA CULTURA EN LA ESCUELA
}

\author{
DANIEL GÓMEZ RAMOS ${ }^{1}$ \\ ORCID: https://orcid.org/0000-0002-4041-1512
}

\begin{abstract}
RESÚMEN: Este texto parte de la inquietud por colocar en el centro de la educación el cuidado del otro y la responsabilidad ante la vida de la infancia, ya que estos saberes pedagógicos favorecen los procesos de aprendizaje y crecimiento personal de los estudiantes. El artículo estudia la experiencia del límite como un encuentro con la propia vulnerabilidad capaz de organizar la subjetividad: generando contornos para existir y enlazando el deseo a la cultura. Desde un enfoque inspirado en la investigación de la experiencia y la fenomenología-hermenéutica, se acompaña a una maestra y sus alumnos en una escuela ubicada en un contexto de dificultad. La descripción de escenas y las conversaciones con la maestra han permitido obtener algunas orientaciones prácticas acerca de cómo acompañar el límite y la norma en la relación educativa, así como realizar una comprensión en profundidad de sus implicaciones en el desarrollo y maduración de la infancia.
\end{abstract}

Palabras clave: Responsabilidad pedagógica, límites, cultura, escuela, infancia.

\section{RESPONSABILIDADE PEDAGÓGICA DIANTE DA EXPERIÊNCIA DO LIMITE NA INFÂNCIA: A INTRODUÇÃO À CULTURA NA ESCOLA}

RESUMO: Este texto parte da preocupação em colocar no centro da educação o cuidado com o outro e a responsabilidade diante da vida da infância, pois esse conhecimento pedagógico favorece os processos de aprendizado e crescimento pessoal dos alunos. $\mathrm{O}$ artigo estuda a experiência do limite como um encontro com a própria vulnerabilidade, capaz de organizar a subjetividade: gerar contornos para existir e vincular o desejo à cultura. A partir de uma abordagem inspirada na investigação da experiência e da fenomenologia hermenêutica, esta pesquisa acompanha uma professora e seus alunos de uma escola localizada em um contexto de vulnerabilidade social. A descrição das cenas e as conversas com a profesora nos permitiram obter algumas orientações práticas sobre como acompanhar o limite e a norma na relação educacional, bem como obter uma compreensão aprofundada de suas implicações para o desenvolvimento e amadurecimento da infância.

Palavras chave: Responsabilidade pedagógica, limites, cultura, escola, infância.

\footnotetext{
${ }^{1}$ Universidad Nacional de Educación (UNAE). Azogues, Ecuador. < danielgomezramos84@gmail.com> Educação em Revista | Belo Horizonte|v.36|e221449|2020
} 


\title{
THE PEDAGOGICAL RESPONSIBILITY IN THE EXPERIENCE OF THE LIMIT IN THE CHILDHOOD: THE CULTURE INTRODUCTION IN THE SCHOOL
}

\begin{abstract}
This text is based on the concern to place in the center of education the care of the others and the responsibility towards the childhood lives. Since this pedagogical knowledge helps the processes of learning and personal growth of the students. The article studies the experience of the limit as an encounter with one's own vulnerability capable of organizing subjectivity: generating contours to exist and linking desire to culture. From an approach inspired by the investigation of experience and phenomenology-hermeneutics, a teacher and her students are accompanied in a school located in a hard context. The description of scenes and the conversations with the teacher have allowed to obtain some practical guidance on how to accompany the limit and the norm in the educational relationship. It also made an in-depth understanding of limits implications in the development and maturation of childhood.
\end{abstract}

Keywords: Pedagogical responsibility, limits, culture, school, childhood. 


\section{INTRODUCCIÓN}

El presente artículo está asociado a un proyecto de investigación ${ }^{2}$ que tuvo la finalidad de indagar sobre los saberes de docentes, y cómo dichos saberes se ponen en juego dentro de las relaciones que se establecen con los estudiantes, y su cuidado; haciendo posible así, mejores condiciones de crecimiento personal y aprendizaje. Este trabajo se concentra en profundizar en la comprensión sobre la responsabilidad y el cuidado de niños y jóvenes en el oficio de educar (Clandinin, 2016; Brailovsky, 2019; Kohan, 2019). El resultado principal derivado del estudio es la manifestación del "cuidado responsable del otro" en la práctica educativa. Se puede observar el sentido ético como una base de acción y guía, una actitud asumida por la parte docente, y la influencia de este posicionamiento en las relaciones educativas que se mantienen con niños y jóvenes.

Las aspiraciones mencionadas han motivado un estudio del cuidado-responsabilidad como un saber producido en una relación de pensamiento con la experiencia vivida, un modo de saber existencial y holístico que se elabora por medio de un pensar creativo con lo que se vive (Contreras et al., 2016; Ayala, 2018). Es un saber emergente, porque dispone a interrogarse por lo adecuado ante una situación singular; pero también es sedimentado, en tanto proporciona un bagaje reflexionado y una orientación para la acción (Contreras et al., 2017; Ávalos, Palos \& Miranda, 2019).

Con el objetivo de percibir las cualidades del fenómeno estudiado con mayor claridad y amplitud de matices, la indagación se desarrolló en una escuela ubicada en un contexto empobrecido de la periferia de Barcelona a la que asistían niños y niñas en particulares circunstancias de vulneración. El $60 \%$ de estos alumnos eran hijos de personas inmigradas a España durante la primera década de los años 2000, el $40 \%$ pertenecían a minorías étnico-culturales (de procedencia gitana, latinoamericana, centroafricana y asiática), además, el $90 \%$ de los alumnos de este grupo formaban parte de familias que presentaban graves dificultades económicas. En el momento en el que se inicia la investigación, esta escuela cumplía los 18 años desarrollando un proyecto de centro basado en tres ejes rectores: 1) la convivencia y el aprendizaje entre diferencias, 2) los lazos sociales desde la patria de los afectos y 3) las relaciones educativas sostenidas en una ética de la hospitalidad.

En el diseño y posterior despliegue de dicho proyecto participó una experimentada docente de la Universidad de Barcelona, que fue el contacto con la directora del centro educativo, y, a su vez, con la maestra con quien se realizó el trabajo de campo para esta investigación. Ambas, la directora y la maestra, fueron las principales iniciadoras y fundadoras del proyecto de centro en un tiempo (alrededor de 1998) de fuertes conflictos sociales en el barrio en el que se emplaza la escuela (inmigración, racismo, tráfico de narcóticos, pobreza, violencia, etc.), un proyecto que pretendía acoger y proteger a los menores de la zona para darles un futuro más próspero que el que les hubo tocado por origen.

De este modo, a través de una referencia directa, se produjo el acercamiento del investigador al contexto de estudio, la posibilidad de trabajar con el grupo de niños y el acceso al conjunto de profesionales y docentes que participaban en la institución escolar. Se decidió acompañar a María ${ }^{3}$ por ser una maestra de extensa trayectoria profesional y especialmente preocupada por el cuidado de la infancia y la responsabilidad pedagógica. Para ello se realizó una observación participante en el grupo P5 de Educación Infantil con 19 niñas y niños a lo largo del curso escolar 2015-2016, compartiendo el día a día en el aula y manteniendo conversaciones reflexivas con la maestra acerca de las cuestiones suscitadas durante la jornada.

\footnotetext{
2 «Relaciones educativas y creación del currículum: entre la experiencia escolar y la formación inicial del profesorado. Indagaciones narrativas» (EDU2016-77576-P), I+D+i financiado por el Ministerio de Ciencia, Innovación y Universidades para el período 2017-2019, dirigido por el Dr. José Contreras Domingo, de la Universidad de Barcelona.

3 Para preservar la intimidad y cuidar a la docente y a los niños con los que trabaja, se ha decido usar nombres suplantados; del mismo modo que tampoco se hace mención a espacios ni lugares concretos para que el centro educativo donde trabaja no pueda ser reconocido.
} 
La investigación no se concentró en los saberes pedagógicos de la maestra, tampoco en un registro pormenorizado de sus buenas prácticas, sino que la intención fue recibir sus formas de hacer y de pensar como situaciones experienciales (Sierra \& Blanco, 2017). Es decir, acontecimientos novedosos que provocaban el pensamiento y necesitaban ser investigados para producir los sentidos y los significados que revelarían las diversas dimensiones pedagógicas que la responsabilidad y el cuidado verifican en el mundo empírico (Sierra, 2019).

\section{MARCO TEÓRICO}

La responsabilidad pedagógica surge cuando las necesidades de un niño o joven son percibidas, pero además de su recepción, ejercen un reclamo de respuesta. Dice Van Manen (2015) que la fuerza de la fragilidad llama a la sensibilidad, y sólo entonces, se escucha como una voz que interpela. El niño o joven otorga la autoridad, que se experimenta como un llamado, para que un adulto actúe de forma cuidadosa con él. El educador se vuelve sensible en la medida en que puede tomar conciencia de lo extraordinario de la llegada de un joven o niño. Esto supone una de-manda de receptividad y vulnerabilidad hacia la experiencia emocional y afectiva que posibilita el encuentro con la alteridad.

La vulnerabilidad de un niño es una llamada a la que se acude, por lo tanto un acontecimiento ético. La preocupación y ocupación por el otro es lo que da sentido al Yo (Lévinas, 2015). Es así que se anuda el lazo social. Tal responsabilidad es la estructura inicial, fundamental y esencial de la subjetividad.

Desde su singularidad, el niño solicita ser ayudado. Una respuesta concreta y situacional consiste en reconocerlo, acogerlo sin condiciones y ofrecerse a acompañarlo (Bárcena \& Mèlich, 2014). La relación pedagógica está arraigada en la responsabilidad ética. La escucha, la atención y el cuidado marcan la dependencia del otro. La respuesta que ofrecemos debe crear un camino para hacerlo progresivamente responsable de sí y de los otros. ¿Cómo interviene el lenguaje ético del cuidado responsable? ¿Cuáles son las implicaciones pedagógicas de esta disposición subjetiva? ¿Qué gestos se exponen en la relación educativa? ¿Cuáles son las implicaciones para la subjetividad del niño?

El presente artículo está enfocado en el análisis del sentido pedagógico de la experiencia del límite en la infancia (Lacan, 2015). Situación dolorosa porque conlleva una cierta frustración, pero organizadora de la subjetividad, en tanto da a la vida unos contornos (una forma) y le imprime una orientación (otra posibilidad que la recurrente). El límite es el encuentro con la propia vulneración y la propia finitud (Mèlich, 2015), por ello, si se realiza en un entorno tranquilo y respetuoso, la imposibilidad despierta el deseo de enlazarse socialmente.

A partir de una escena escolar y de fragmentos de conversación con la maestra, se indaga en el trasfondo ético del límite y se aportan algunas claves para acompañar a los niños en la emoción traumática del contacto con la ley de lo humano (Recalcati, 2014). El encargo del educador consiste en transmitir un orden normativo e invocar el deseo por la cultura que, a cambio de una pérdida de instinto, ofrece al niño la filiación en un mundo común (Bárcena, 2012). Sin embargo, sólo si el educador se somete a sí mismo a la ley del deseo responsable, sólo si éste asume la limitación de su soberanía sobre los otros, podrá ser símbolo del límite y recibir la autoridad significativa concedida por el niño.

\footnotetext{
${ }^{4}$ Este epígrafe esboza un primer marco teórico, puesto que las referencias conceptuales se van desarrollando a lo largo de todo el cuerpo del texto con el objetivo de sostener un diálogo indagador entre la literatura especializada y los materiales sensibles.
} 


\section{METODOLOGÍA}

El saber pedagógico responde a una construcción compleja. Abarca emociones, relaciones, valores, corporalidad y ética. Bajo estas consideraciones, la metodología para la investigación precisaba basarse en la experiencia educativa y en la fenomenología-hermenéutica (Gadamer, 1977; Dewey, 1998; Van Manen, 2003; Contreras \& Pérez de Lara, 2010; Clandinin, 2018) con el objetivo de pensar con la experiencia y producir sentido. De esta forma la indagación compone una disposición subjetiva, mediante la que la escuela es habitada desde la exposición y recepción de la alteridad de los otros, del mundo y de uno mismo. El fenómeno se atiende y se capta con la sensibilidad que despierta una inquietud. Esta turbación da forma a un signo o bilo de sentido que requiere del pensamiento para su significación (Arbiol, 2018).

$\mathrm{Si}$ algo resuena subjetivamente es porque la situación vivida despierta una pregunta o conecta con una necesidad, signos que hablan de una búsqueda de sentido pedagógico. El hilo de sentido es experimentado por la reflexividad como el acontecer de una exterioridad que nos "deja pensando" o que nos "da que pensar". Desde diversas orientaciones (Biesta, 2017; Skliar, 2017; Najmanovich, 2019) se entiende el acontecimiento como un encuentro entre la experiencia y el pensamiento que tiene el poder de desplazarnos de lo conocido y del propio punto de vista, cuestionar lo que damos por sentado y provocar duda en lo que decimos. Lo que acontece afecta al significado de nuestras acciones y actitudes porque abre las hace susceptibles a una nueva elaboración.

El desarrollo de la investigación reconoce siete momentos. En primera instancia la percepción directa del fenómeno. La escritura del diario de campo. Las conversaciones grabas y luego transcritas. La identificación de interrogantes e hilos de sentido. La construcción de los textos de campo, en forma de fragmentos y escenas. Un corpus teórico extenso que acompaña todo el trayecto. La elaboración de textos de investigación, a través del ensayo como modo de interpretación y reflexión. Todo el proceso se produjo entre la observación y análisis diario en la escuela, es decir, mediando la confrontación de lo hallado y las interpretaciones dilucidadas con la alimentación teórica y constantes revisiones, lo que corresponde a una triangulación ambiental (Meneses, Rodríguez \& Valero, 2019). El tratamiento investigativo se da como una comprensión más profunda y contextualizada del tema estudiado. La escritura resultante ha sido puesta en cuestión previamente, por lo que se torna un producto confiable, en tanto en cuanto permite al lector reconocer en el texto sus inquietudes y hacerse sus propias preguntas.

Los momentos de la investigación no dejan de ser simultáneos, pero metodológicamente inician con la percepción in situ del fenómeno. Lo sucedido, vivido y pensado en la escuela, al igual que las palabras que se compartían con la maestra al respecto, quedaron plasmadas en las anotaciones del diario de campo. A partir de esa escritura, surgían narraciones en forma de escena (ESC) o fragmento de conversación (FC). Un texto de campo que no lo dijera todo de la experiencia, que no clausurara su potencia significativa, pero cuya lectura tuviera la capacidad de suscitar los interrogantes que se habían desvelado al investigador (Meirieu, 2016).

Una escena o un fragmento de conversación muestran un material sensible con el que seguir elaborando un pensar con la experiencia con el que trazar diversos caminos de escritura mediante los que ir ahondando reflexivamente (Foucault, 2018) en las dimensiones pedagógicas que había implicadas en el fenómeno registrado. El descubrimiento de temáticas de investigación se da a partir de la interacción entre el material experiencial-sensible: los textos recabados, con un corpus teórico variado: literatura pedagógica y filosófica. Fue ahí donde las interrogantes de investigación robustecieron y los hilos de sentidos fueron captados, para su posterior exploración. Los textos investigativos comprenden un trabajo de profundización de aquellas cuestiones educativas que emergieron de los textos compuestos durante la estancia en la escuela (textos de campo). Para esta ampliación se recurrió a la escritura ensayística (Lukács, 2016; Adorno, 2018), porque el ensayo procede indagando experimentalmente con el tema de estudio desde vertientes diversas y lo hace estableciendo con lo vivido una distancia poética: creando, revelando o trayendo al presente 
algo valioso (Agamben, 2019). El lenguaje del ensayo, frágil y heterogéneo, combina la presencia del sujeto que escribe con la atención constante a la pluralidad y transferencia de conocimiento de la investigación educativa.

\section{RESULTADOS Y DISCUSIÓN}

Los resultados están descritos como hilos de sentido. Partiendo de los propósitos de investigación, el tiempo de la escuela como experiencia vivida y la identificación de signos de los acontecimientos se conduce una elaboración conceptual (Deleuze \& Guattari, 2013). Debido a que el estudio es más amplio, aquí se muestran tres secciones, donde constan los asuntos más relevantes que se han investigado con exhaustividad. Los textos dan cuenta de un pensamiento que produce efectos de sentido y buscan responder a la multiplicidad semántica de lo real (Larrosa, 2017).

\section{LA IMPOSIBILIDAD COMO ORIGEN DEL VÍNCULO SOCIAL}

¿Cómo experimenta un niño la relación con "lo que no puede"? ¿Qué significa, para una subjetividad, el encuentro con el límite? ¿Cuál es su sentido pedagógico, o, qué limita el límite?

Los límites forman parte de la vida como contacto con ciertas zonas no traspasables (Lévinas, 1993, p.84). Las situaciones límite son umbrales irreversibles que, a menudo, nos afligen y desesperan. Cuando aparecen, queremos evitar la tensión que llega como experiencia de la fragilidad. De pronto, el propio vivir se revela provisional, precario en su bagaje. El propio poder se ve subordinado a la contingencia, "no poder" nos desvela en una atención incómoda. Según Emmanuel Lévinas (2015, p.222), padezco mi finitud como "presencia de la humanidad en los ojos que me miran", tensión conflictiva por el cuidado de sí, de los demás y del mundo. Por eso lo limítrofe es el momento del hilván, del lazo, con lo otro. Límite es choque con la diferencia del otro, pero también, con la propia diferencia. Alteridad del otro en el Mismo que emerge en el acontecimiento de lo imposible: "el poder del Yo no franqueará la distancia que indica la alteridad de lo Otro" (p.62). De ahí que el límite nos pregunte por nuestra conciencia y, acerca de ella, nos ofrezca pistas para un sentido. Pues si el límite forma parte de la vida, el límite da a la vida una forma. En tal caso, hacer frente a la situación límite es tener la oportunidad de dar a la existencia una dirección. La imposibilidad del Yo de absorber la alteridad, de participar en un mismo concepto, señala la posibilidad de un trascenderse a sí. "La relación con el otro cuestiona la brutal espontaneidad de mi destino inmanente, introduce en mí lo que no estaba en mí” (p.217).

¿Podría entenderse la ek-sistentia como estar en el límite y lo humano como ser límite? Si el límite es legible como zona de vulneración, entonces, el límite implica la necesidad del lazo. Es decir, unión que cobija y nos lleva hacia ser de otro modo, dice Lévinas (1987, p.213): un "yo abordado a partir de la responsabilidad para-con-el-otro es desnudamiento, exposición a la afección, pura suscepción". Proximidad del uno y del otro en una implicación totalmente distinta a la del compro-miso; asignación enigmática que nos reúne en la búsqueda de escucha y comprensión. El contacto limítrofe de la alteridad nos pone fuera de nosotros mismos, inaugura la situación vulnerable e intrigada de la existencia (p.134). La persona es límite y por tanto es lazo, vive enlazándose con otros y con lo otro mediante el lenguaje y el pensamiento. Estar limitado conlleva una demanda de abrigo y de luz dirigida a los demás. Estar limitado significa ponerse en movimiento, o sea, búsqueda inacabable de sentido. Por eso el límite no sólo hace referencia al final de algo, sino también, al acontecer del comienzo de otra cosa.

Para visualizar y ahondar en estas cuestiones, presentaremos ahora una escena registrada durante el trabajo de campo en la escuela:

Vuela una taza de plástico dibujando un arco en el aire y cae en el lavabo del aula. Rebota con ruido estrepitoso y sale despedida hasta los pies de Jorge. El niño recoge la taza del suelo y vuelve a lanzarla en un tiro oblicuo hacia el lavabo. De nuevo el estallido del plástico contra el mármol. Repite la misma acción cinco o seis veces y, entonces, dice:

Educação em Revista | Belo Horizonte|v.36|e221449|2020 
JORGE: Quiero canastarla.

La maestra regresa de acompañar a los niños al comedor y observa lo que sucede. Toma la taza de las manos de Jorge y la coloca junto a las demás en los ganchos destinados a tal uso.

JORGE: ¡Dámela! ¡Que quiero canastarla!

MARÍA: No. Las tazas no son para jugar, son para beber.

El niño comienza a llorar con una rabia que aumenta progresivamente.

MARÍA: Si quieres lanzar y encestar puedes ir al patio con un pelota y la canasta de baloncesto. Si quieres estar en el aula has de respetar esta norma.

Jorge se deja caer al suelo, se estira y expresa una fuerte angustia, dando patadas al aire y arrastrándose a empujones con las manos. La maestra se acuclilla cerca del niño; permanece en silencio, a su lado. Espera unos minutos dándole, verbalmente, permiso para soltar su malestar.

MARÍA: Venga cariño, tu mamá no tardará en llegar. Vamos a quitarte la bata y a ponerte el abrigo.

JORGE: ¡No, no! ¡Quiero canastar la taza! -grita con la cara roja y la frente sudada.

MARÍA: Ya está bien, Jorge. Vamos a levantarnos y ponerte el abrigo.

Para levantar al niño del suelo, la maestra lo toma con mucha dificultad. Jorge se resiste. El aire se lleva algunos puñetazos y una mesa recibe un par de puntapiés.

MARÍA: ¿Has visto la rabia que tienes? - dice mientras se queda junto a él para evitar que se haga daño.

Jorge llora y da gritos que no articulan palabras reconocibles, parecen llanto, desahogo. María se acerca de apoco, le pone las manos en los hombros y luego en la frente, secándole las gotas de sudor, acariciando su pelo. Así pasan más de cinco minutos y el niño va serenándose (ESC_5).

Los límites son puntos de apoyo necesarios para orientar la capacidad de vivir en el mundo. Son los contornos de un puzle, sin los cuales, sería imposible componer pieza por pieza un cuadro con sentido. Son las orillas que encauzan el agua del río, sin las cuales, el agua se desborda y el río desaparece. Según Rebeca Wild (2015, p.56), en la experiencia del límite desarrollamos nuestra estructura subjetiva. Subjetividad que es acontecimiento de lo otro que desarma al Yo y lo expone (Lévinas, 1987. p.100). En el encuentro con la exterioridad es donde configuramos nuestra realidad interna. En ese encuentro, los límites son imprescindibles para llegar a actuar con libertad. Una libertad que requiere unas fronteras que protegen al niño $-y$ al mundo- de su impulsividad. Sin embargo: ¿qué sucede cuando un niño no ha tenido ocasión de estructurar unos con-tornos en su organización interna? ¿Cómo ofrecerle modos de ordenar su manera personal de manejarse con sus impulsos?

"Los niños -y naturalmente también los adultos- que nos causan preocupaciones o que son objeto de queja, en el fondo sufren una falta de libertad" (Wild, 2015, p.57). De ahí tomarse "libertades" que no les corresponden, superar los límites de los demás y desatender los suyos propios. Niños y adultos que, en esa debilitada libertad, se sienten angustiados y desorientados. Libertad fragilizada por la privación de un continente simbólico que contenga su existencia. Unas referencias que asistan y guíen al niño para entrar al mundo desde la claridad y el cuidado.

La introducción de la singularidad de una infancia en la pluralidad del mundo pasa por el aprendizaje de lo imposible. Aquello que lo diferencia de lo otro y le permite construir un "yo en el mundo". Aquello que asume como "no poder" y le permite conocer su poder. El límite funciona como frustración del impulso hacia todo propio de la naturaleza (Recalcati, 2016, p.87). Pero no una frustración excesiva que acabe agotando o desalentando la capacidad deseante. Sino una dosis adecuada de frustración que, al separarlo de lo Mismo de sí mismo, despierte su deseo de alteridad. La aparición en uno del deseo de otro es lo que, según Emilio Lledó (2005, p.107), construye -de lo animal- un mundo humano.

Es tanta la rabia que tiene, que no le vale nada. Ni jugar con sus compañeros, ni pintar o relajarse, ni concentrarse en una actividad... Tiene que ser una acción más fuerte que le ayude a sacar toda la porquería que lleva. Que no sé cómo se le ha alimentado con eso. Si está enganchado en esa pena el niño no está bien y no es libre. Ellos necesitan herramientas para vivir. Y límites para aprender a regularse y conocerse y vivir tranquilamente con los demás. Pero si en casa no han tenido estos límites, pues ya has visto, están enganchados en su pena (MARÍA_FC_11). 
Los límites no sirven para inculcar obediencia; no son instructivos en sí mismos. Cuando el grande los marca atendiendo la experiencia sentimental del pequeño, sirven de orientación. En un espacio de vida tranquilo y respetuoso, los límites nos proporcionan la facultad de estimar nuestras fuerzas (Wild, 2015, p.48). Regulaciones estructurantes que el niño subjetiva como conciencia de sí y de lo otro. En la escena narrada, Jorge quiere encestar la taza en el lavabo del aula, pero: ¿cuál es el deseo que se expresa ahí? Si el significado es la interpretación -la traducción- que hace la conciencia de un significante inconsciente (Lacan, 2010, p.206): ¿el significado (la petición, la querencia) y el significante (la necesidad, lo ausente) se corresponden, son coincidentes? Tal vez la maestra discierne que Jorge está sustituyendo, con una "acción más fuerte", una carencia propia de su desarrollo humano. "La rabia y la pena que tiene" serían, quizás, expresiones de una sensación. Sensación de cierto abandono en la solitaria intemperie, es posible: reclamo de amor por estar originalmente partido (Lledó, 2005, p.108).

Hay un desorden esencial, un "no saber" en el fondo del deseo, que nos mueve a buscar las huellas de la forma original (Lévinas, 1993, p.127). Después de la pérdida primordial surge la necesidad de completarse, la cual provoca una tensión. Estar partido, estar limitado, es estar tanteando las huellas de la memoria y los senderos del presente. Puesto que el ser fracturado es insuficiente, anhela ligar su límite al límite del otro para estabilizar su frágil existir. En tanto ser simbólico, su palabra necesita de la otra mitad del diálogo y la interpretación para realizarse (Lledó, 2005, p.109). La ligadura con el mundo humano compensa nuestra imposible autarquía. Hilván que se hace presente por la mediación de Eros (Lévinas, 1993, p.132). El amor es deseo que tiene por causa el ser simbólico, es decir, el ser límite es la génesis del deseo.

El carácter de "fragmento" de la palabra manifiesta su reclamo de un escuchante: otro ser simbólico donde encontrar la imprecisa mitad perdida. El deseo ocurre porque no hay vida vivible sin estar enlazada con alguien (p.46). No obstante: ¿qué sucede si un niño vive su palabra atenazada o rechazada por la presión, las dificultades o las inercias familiares? ¿Cómo acompañar la indigencia de su lenguaje en el curso hacia la socialidad donde su discurso sería reconocido? "El mundo afectivo que enlaza tantas interpretaciones, y adorna y fecunda los lazos sociales, nos en-vuelve también en la violencia", dice Lledó (2005, p.112). Cuando la palabra del niño se pierde en un entorno social invivible, el deseo de amor se apaga en un continuo vagar en soledad. Cuando los lenguajes de sus mayores han encerrado al niño en una jaula de hierro, su estar partido queda sin la compensación simbólica del otro (p.113). Ante la inconsistencia de unos adultos que garanticen una traducción solícita, el cuerpo manifiesta una desesperación.

Toda palabra es pieza partida que necesita ser reconocida por el lenguaje fracturado limitado- del otro. Cuando el discurso del grande se desentiende de completar el discurso del pequeño, su palabra se extingue y el deseo se reduce a instinto (Lacan, 2010, p.205). Energía libidinal desregulada (p.264) que la maestra limita: "no te dejo lanzar la taza" y abre camino hacia otro lugar donde realizar el deseo: "si quieres encestar, hay pelotas y canasta en el patio". Representa una norma que el niño vive con dolor y consecuente protesta, ¿cómo acompañarlo en la emoción traumática del límite? María se queda al lado de Jorge, amparándolo en su experiencia de lo imposible. Acompañando el duelo que el niño vive de una parte de sí mismo, la pérdida del impulso hacia todo propio de la naturaleza (Recalcati, 2014, p.29). En tal caso, se trata de no intervenir desde la impaciencia o el enojo sobrepasado. De sostener el límite y al niño, a la vez, sin cancelar sus sentimientos con explicaciones o justificaciones innecesarias. De encarnar la palabra tierna y cariñosa, pero firme y clara, de un lenguaje que es cálida morada para el niño. Aún así los límites son dolorosos, nos dice Wild (2015, p.93), pues nadie choca contra una pared sin hacerse daño.

¿Lo hacemos desde un esfuerzo de coherencia y una presencia afectuosa, o lo hacemos cuando ya hemos perdido la paciencia y por tanto desde el enfado y el reproche? Según Wild (2015, p.47), "en lugar de muchas palabras lo que el niño necesita es un adulto que acepte su dolor, que no quiera intentar desviar su atención o enseñarle, que le deje llorar o protestar sin disuadirle de sus sentimientos ni de sus pensamientos". Favorecer un recorrido por el que Jorge 
pueda detenerse ante la impotencia y enfrentarse a la norma, para elaborar su potencia como sujeto deseante (Lacan, 2015, p.476). ¿Con qué de la cultura podría el niño ligarse para, así, desligarse de la pena y la rabia que lo enganchan? ¿Qué del mundo ofrecer para que su deseo pueda enlazarse y salga, así, de su fijación imaginaria? ¿Cómo aplazar la satisfacción que Jorge encuentra tirando la taza en el aula, para orientar su atención a lo otro y los otros?

La maestra redirige al niño a un entorno preparado para la expresión de su energía, su deseo es canalizado hacia un marco normativo capaz de realizarlo (Wild, 2015, p.20). Marcar un límite con respeto implica que respondo a la demanda de una criatura, comprendo que el deseo es una búsqueda que pone en movimiento los recursos del sujeto. Búsqueda que debe vehiculizarse mediante el cuidado y la atención hacia las cosas y las personas. No ignoramos o despreciamos el empuje de esa búsqueda, tiene valor en su desarrollo, nuestra responsabilidad es orientar su sentido hacia lo humano (Lledó, 2005, p.135). En la escena narrada, María parece guiar a Jorge a un lugar donde actualizar su potencialidad sin dañar ni dañarse. Lo que no puede hacerse en el aula, sí se puede y es bienvenido en otro lugar. La necesidad del niño es acogida por un orden simbólico donde inscribirse y pertenecer habitando junto a otros (Bárcena, 2004, p.153).

El límite no es agradable para el niño, sin embargo, apoya sus capacidades y habilidades cuan-do responde a una necesidad de regulación interna. Cuando responde a la formación del sentido de medida y de moderación: modulaciones personales de la relación con los otros, con el contexto y consigo. Según Philippe Meirieu (2015, p.86), nadie es del todo autónomo, nadie es un ser suficiente ni se basta a sí mismo, la progresiva construcción del "yo en el mundo" se funda en vínculos heterónomos. Son los otros y la cultura lo que nos salva del infierno de lo igual de nosotros mismos; aunque algunos otros y algunas intenciones pueden hundirnos en la miseria de su buena conciencia (Bárcena, 2004, p.26).

El educador pone freno a las pulsiones con las que la vida se deshumaniza para inaugurar vías por donde pueda emerger el deseo y el esfuerzo por la alteridad. Dice Freud (1992, p.60): "las pulsiones vitales acarrean consigo estados de tensión cuya resolución es experimentada como placer; el principio de placer parece estar directamente al servicio de la pulsión de muerte". Por tanto, limitar el placer egológico produce, a la contra, nuevas derivas en el repertorio de recursos de un sujeto. El niño padece el impasse de una decisión al confrontar el hecho de que su libertad significa responsabilidad para con el otro (Lévinas, 1987, p.52). "Si quiero estar en clase he de respetar las normas, si quiero jugar a encestar tendré que salir al patio". Lo cual supone que, des-de muy temprano, se establezcan leyes y prohibiciones. Reglas que sólo tendrán sentido pedagógico si, por otra parte, autorizan a otra cosa y si el niño así lo experimenta (Meirieu, 2015, p.82). Entonces, esas normas son la condición de su libertad en un espacio de seguridad física y afectiva. La criatura intenta nuevos aprendizajes sin preocuparse de su torpeza, porque siente que hay alguien ahí que no la dejará sola. A la hora de limitar la satisfacción de una pulsión (tendencia frenética por regresar a la paz de lo inorgánico) se ha de ofrecer, a la par, un buen lugar donde el niño pueda materializar su energía. De lo contrario, una excesiva frustración conlleva un dolor con el cual, quizás, no esté preparado para manejarse.

El educador no abandona al niño a sus circunstancias, reduciendo su experiencia a los encuentros casuales que pueda tener. Sino que acompaña al niño asociando sus interrogantes con la cultura humana, introduciéndolo en la herencia (Bárcena, 2012, p.73). El educador es aquel con quien el niño puede intentar confrontaciones e intercambios y en ello descubrir la semejanza que le permitirá escapar de su soledad. El educador es alguien que reconoce la semejanza en el niño más allá de las inevitables diferencias. Por eso el niño encuentra en el educador un lugar donde descansar y configurar su propia conciencia. El encargo del educador es componer un continente cultural para el recién llegado y, por un tiempo, ayudarle a que se mantenga en él en pie (Meirieu, 2015, p.85). Las criaturas que no disfrutan de este tipo de espacios y referencias donde habitar subjetivamente, ni disponen de una autoridad adulta significativa, se verán reducidas a la violencia como única alternativa posible para mantenerse en pie ante el hundimiento y "existir al menos a ojos de aquél a quien se agrede" (p.84). 


\section{SER «LÍMITE VIVIENTE» Y OFRECER UNA CULTURA}

Las nociones "lazo" y "enlace" vienen del latín laqueus que significa nudo o liga, su raíz onomatopéyica $l$ (más vocal) designa el gesto y el sonido de la lengua en la experiencia lactante del amamantamiento. Lamer o saborear la leche es el acto en que se expresa el amor del deseo satisfecho en la relación de dependencia materno-filial. De ahí la descendencia indoeuropea del racimo *leubh (amar, desear) que irradia la idea de alabanza en aquella persona que es loable: agradable y de confianza. No en vano, de la misma fórmula fonética l de lazo (laqueus), leche (lac) y lamer (lei) derivan love en inglés, Liebe en alemán o liefde en holandés: amar vivamente; y también lipto en griego, lioef en anglosajón y libido: desear con intensidad.

¿Y si el mismo término "lamer" estuviera vinculado con limes, con "límite"? Entonces la mama de la madre es el primer límite y el momento en que su significado de "separación" confluye con el de "alimento". El límite de la mama es el lazo con la alteridad pre-liminar donde uno se nutre del Otro (de lo otro) inspirando el campo semántico que nos traerá la maduración y la transformación: el límite es "lugar de alimento" que permite el porvenir de la formación y el devenir otro modo de ser. De hecho, es curioso que en el vocablo análogo limitrophus encontramos una hibridación entre el latín limitis (linde, confín, borde) y el verbo griego tropheo cuya raíz *trepho quiere decir "nutrir a", "alimentar a", "guarnecer a" o "sustentar a" lo que indique la primera palabra. De nuevo: lo limítrofe es la zona del alimento; donde el alimento se extiende, ya en sentido amplio, a los afectos, los efectos y las acciones de la relación con el mundo.

Quiero decir, educar es eso, primero y fundamentalmente. Es un poco ir aprendiendo a caminar hacia los aprendizajes del currículum. Pero hay cosas aquí, que veo que han de pasar antes que otras.

Por ejemplo, el mes pasado nos pasaron las competencias y los conocimientos básicos que han de superar. Y yo me pregunto: ¿lo más importante son las competencias básicas? ¿Alguien se ha preguntado si los niños están bien? ¿Alguien se ha preguntado cómo están los niños? No. Preguntamos por resultados. ¿Y cómo se sienten? ¿Cómo viven la escuela?

Dicen que hay muchos niños que están atendidos por servicios, por la psicología, por otras terapias... o que se les da alguna medicación. Pues para mí, si necesitan terapias es que las competencias básicas no pueden salir bien. Porque son cosas del afuera del niño. Y para mí es más importante el interior del niño. Para que pueda moverse de dentro hacia fuera. Que salga desde su interior a encontrarse con el mundo.

Si están mal de dentro, qué les vamos a venir con las letras y los números. Si son cosas del afuera, un código que hemos creado sin los niños. Un código al que ellos, primero, han de estar en condiciones de poder acceder. ¿Qué no son más importantes como personas? Sus procesos de hacerse personas. La relación con la cultura, con el mundo y con los contenidos está aquí porque esto es una escuela. Pero la mirada yo la pongo en facilitar unas relaciones personales y unas condiciones primeras para el aprendizaje (MARÍA_FC_12).

Dice María que "hay cosas aquí que han de pasar antes que otras", dando a pensar que el educador oficia presentando una gramática. Según Joan-Carles Mèlich (2015, p.17): “un juego de lenguaje, el conjunto de símbolos, signos, hábitos, ritos, valores, normas e instituciones que configuran un universo cultural". Un lenguaje que limita ciertas formas de interacción de los niños, para reorientar su deseo hacia relaciones de cuidado de sí y de los demás. Atender a "cómo están los niños" para ayudarlos a encontrarse en condiciones de interesarse y acceder a las tareas escolares. Por un lado, la criatura desarrolla sus capacidades y habilidades siguiendo un empuje interior de relación libre y creativa con el mundo (Wild, 2015, p.160). No repara en explorar, imitar y modificar para crear del desorden un orden propio. Y por otro lado, durante esos tanteos y recorridos en los que va en busca de un sentido personal de lo que vive, debe encontrarse con imposibilidades. Con los límites sociales y culturales en los que lo humano llega a realizarse en el sujeto (Lledó, 2005, p.60). Es decir, debe aprender aquello que se puede esperar que acepten los otros, las costumbres, las normas del contexto y lo que conviene o no en cada circunstancia. 
En la escena narrada, se podría considerar que María intenta poner un límite con respeto: hay algo en lo que se juega en la situación de una presencia afectuosa, de una sensibilidad receptiva a la experiencia del niño. ¿Cómo hacer la mediación entre el malestar que "mantiene al niño enganchado" y la atención que lo pondría a interesarse por el mundo? Para Wild (2015, p.109), lo primero es no dejar al niño solo en el momento difícil del límite, cuando siente irremisiblemente dolor y posiblemente entre en contacto con un dolor antiguo no procesado. Si se siente acompaña-do y apoyado, tiene la oportunidad de desahogarse del dolor llorando.

El educador encarna el límite, la mirada del niño cae sobre él como acusación ética (Lévinas, 1987, p.183): está llamado a responder de su sufrimiento. El educador es símbolo del límite, su respuesta es siempre incompleta: débil, provisional e irreparable; aun con ello, está requerido a cargar con la vulnerabilidad del recién llegado. La claridad del límite que marca el educador, con-cierne y se asienta sobre la búsqueda personal de sentido pedagógico (Bárcena, 2012, p.59): coherencia entre sentimiento y pensamiento, entre situación y discurso. La absoluta fragilidad de lo humano bajo el azar de lo imprevisto significa para el educador una exigencia ética de orientación (p.75). Petición de contornos gramaticales donde el niño pueda fundar su ser como cuerpo del lenguaje. Reclamo de una autoridad desprovista de dominación: alguien responsable de transmitir no sólo un cierto orden moral sino también, al mismo tiempo, la facultad ética de quebrarlo y reinventarlo (Mèlich, 2015, p.72).

"Soy yo quien no te permite tal cosa", María se coloca como "límite viviente" (Wild, 2015 , p.92) entre el niño y su poder ilimitado que parece conducirlo a no respetar nada -a no atender a nada, a no interesarse por nada-. Jorge gana un adulto ante quien enojarse y contra el que rebelarse. Un adulto con quien expresar su vulneración esencial con garantías de ser abrazado incondicional-mente. Una relación donde diferenciarse, dar cuenta de sí y empezar a componer una forma de vida (Mèlich, 2014, p.180). La maestra no abandona al niño bajo el peso de una lógica ontológica impersonal, de un poder total desprovisto de cuerpo sensible, de una moral sin otro que no admite ninguna duda (Mèlich, 2015, p.48). Ella responde en persona del límite que marca, dicho de otro modo: el educador ha experimentado en sí esa misma regla, esa norma ha dado forma a su vida. En este sentido, el límite transmite el único mandato ético, según Lévinas (2015, p.272), una prohibición del homicidio semiótico: "no matarás", pero antes: "no te matarás".

Ser límite viviente implica que la palabra encarnada del educador produce la castración del goce autodestructivo en el niño. La castración quiere decir, según Jacques Lacan (2013, p.338), "que el goce debe ser rechazado para que pueda ser re-alcanzado en la escala invertida de la ley del deseo". Sublimación de la pulsión de muerte, freno de la satisfacción inmediata del solipsismo alucinatorio (Freud, 1991, p.18) o protección de su vitalidad. Apoyo para la activación y el mantenimiento del deseo de saber que necesita la irrupción de lo extraño atópico para suscitar el interés (Han, 2014, p.10). La vitalidad del deseo se presenta inhibida cuando, a una criatura, se le ha negado repetidamente la posibilidad de pensar y de sentir partiendo desde sí: orientación hacia "lo Otro" que abre la dimensión de su interioridad (Lévinas, 2015, p.304). En tal caso, la familia y el entorno social pueden cometer la perversidad de fabricar a un niño en lugar de educarlo. Ignorando la responsabilidad de introducirlo y presentarle el mundo: preparar sus códigos culturales, disponer unas materialidades y mediar para su recibimiento (Bárcena, 2004, p.95).

Fabricar a un niño y renunciar a su interpelación ética -su advenimiento substituye al Yo del propio centro (Lévinas, 1987, p.182) - es correr el riesgo de hacer de él un monstruo. Si es un monstruo es porque ha sido abandonado por sus mayores. Puede aprender muchas cosas gracias a sus cinco sentidos y a una variedad de encuentros, pero le falta lo humano esencial, dice Meirieu (2015, p.60): nadie se ocupa de su educación, nadie lo acompaña para entrar en relación con los otros.

Afortunadamente, nunca nada se concluye de una vez y para siempre, para lo humano del su-jeto existe la posibilidad de la formación. La posibilidad de la transformación que requiere de Otro capaz de sostener al niño. Capaz de mediar entre los huecos de su subjetividad y los signos 
y objetos de la cultura que le ayudarán a modificar su estructura interna (Lacan, 2010, p.192). Nada se clausura definitivamente mientras haya alguien que repare esa caída inicial de una infancia, alguien que complete el ser partido que somos todos en origen. Mientras exista la oportunidad de elaborar significados que ofrece la educación y la relación con un buen entendedor (p.216).

El educador es símbolo de la ley del lenguaje sólo si ha asumido y asume sobre sí mismo el evento del límite (Recalcati, 2014, p.35). Sólo mostrándose él mismo sometido a la experiencia de lo imposible, podrá vehicular la ley como acotación del Yo narcisista. Si no aceptara la prohibición del goce posesivo y la tentación de dominarlo todo, la gramática se reduciría a una imposición autoritaria. Para Lacan (2015), el educador será aquel que sepa combinar -y no oponer- el deseo del otro con el sentido de la ley. El educador no hace la ley sino que responde de ella, carga a su espalda con la función de límite. Es el respeto por la cultura lo que convierte al educador en tal. No se identifica con la titularidad de esta ley del deseo, puesto que está obligado a la pérdida de su soberanía sobre el otro. Para que el lenguaje pueda transmitirse, el educador debe aprender su propia limitación y albergar en sí el deseo de ser amado. Representar la ley será posible sólo si quien lo hace ha integrado en su corazón la lucha ética (Lévinas, 1993, p.116) entre la pulsión de muerte (propio de la naturaleza) y el deseo de otredad (que hace lo humano). Actuar como portador de la palabra supone haber padecido la prohibición de predominar sobre los demás. Incorporar en sí la vulneración humana y admitir la fragilidad de la vida ante la contingencia, son los gestos precedentes que permiten otorgar a otro la cultura como fundamento del deseo (Recalcati, 2014, p.39).

\section{LA LEY SIMBÓLICA DEL DESEO RESPONSABLE}

Porque en el fondo hay una parte de Jorge que no es eso lo que quiere. Pero el entorno, la presión, la mochila y todo, lo supera. Es una lucha consigo mismo. Y alguien ha de decirle "no, ahora yo te paro aquí, porque hay una parte de tu ser que tengo que proteger".

Porque si no lo hago es como si Jorge, Leonel, Javier o Lucio entraran en un proceso autodestructivo de su persona. Directamente. Pero hay una parte del ser que no está por su autodestrucción. Y entonces es protegerlos de ellos mismos. Es como hacer la protección de uno mismo. Hay la protección de ti mismo, y a la vez es este acompañamiento. Creo que el maestro ha de hacer este acompañamiento, si el niño está así, que es educativo.

Como cuando a Jorge le digo "basta, basta, ya está, estamos aquí, mírame". Yo cuando miro a Jorge lo enraízo aquí con la mirada, lo bajo. No puedo darte una demostración científica de cómo lo bajo. Pero si yo lo miro y lo tomo de la mano y le digo "Jorge, estás aquí, mírame, estás aquí en la clase, se ha acabado". Porque soy su maestra no puedo permitir que se cuelgue en no sé qué galaxia que se va. Porque eso que hace de dar vueltas y marearse es una manera de evadirse del presente. Es una negación de que está aquí. Una forma de desconectar, de irse.

Entonces cuando hago esto es un "stop", es decir "Jorge, despierta, estás aquí, te gustará o no te gustará donde estás, pero estás aquí, por tanto la realidad es esta, hay una realidad física y es esta”. Y es "pam". Es con la mirada porque es con la mirada donde voy. Yo siento que voy. Porque lo miro y lo miro. No lo miro normal. Yo siento que hay una parte de mi mirada que va hacia allí y lo estira y lo enraíza y dice "eh, estamos aquí". Lo cojo de la mano y "basta, se ha acabado, no puedes perderte más porque no te sirve de nada". Allá donde entra no le aporta nada. Presente. Ahora y aquí (MARÍA_FC_13).

La condición vulnerable de toda criatura demanda unos adultos que la ayuden a afianzar, poco a poco, unas capacidades que le servirán para desenvolverse en la dificultad y para construir sus propios saberes por ella misma (Meirieu, 2015, p.23). Educar oficia, según María, "protegiendo al ser del niño que no está por su autodestrucción”. El educador limita -diría Lacan (2007, p.253) - la satisfacción del goce mortal del programa instintivo para abrir al sujeto hacia nuevas formas de vinculación con el mundo.

La palabra de María es ley que baja a Jorge a la tierra, por así decir, de su cielo de fantasía (compulsión de repetición como goce que mortifica su deseo) (Lacan, 2008, p.41). El tacto de la maestra funciona como contacto con lo exterior de su carcasa narcisista. Lo saca del influjo de la 
presión de su contexto y lo enraíza al momento presente: "Eh, estamos aquí". Para despertar la atención a lo escolar, hace falta encender el deseo de conocimiento. La enseñanza podría definirse, dice Daniel Pennac (2008), como una lucha contra el pensamiento mágico, acabar con él para que suene, en cada curso, la hora del despertar:

Aquel pensamiento que, como en los cuentos de hadas, nos hace prisioneros de un presente perpetuo. Acabar con el cero en ortografía, por ejemplo, es escapar del pensamiento mágico. Se rompe un maleficio. Se abandona el círculo. Despiertas. Pones un pie en lo real. Se ocupa el presente de indicativo, se empieza a comprender (p.143).

Quizás, Jorge se agazapa en la galaxia de su pensamiento mágico como un modo de sobrevivir ante la prolongada privación de límites firmes, claros y respetuosos. Un contorno de referencias simbólicas que le aportarían la seguridad -física y afectiva necesaria- para salir del obcecado fon-do de su hechizo y aventurarse por los inexplorados senderos de la realidad. Dada la frustración de este legítimo requerimiento de contención, no es que el niño se evada de lo real perdiéndose en su imaginación (Freud, 1991, p.239), sino que el niño vive un duelo de algo que nunca tuvo: los trazos de un lenguaje con el que dibujar su silueta en el paisaje. Tal vez el niño recurre a su fantasía, no porque allí encuentre esa palabra ausente del Otro, sino porque allí es donde él se vuelve ausencia para sí mismo. "No estar" como una manera de sentir una ilusoria protección ante lo inestable del exterior y frente a la desconfianza de sus mayores. "Si no estoy aquí, si me escondo en mí mismo, no necesito nada y por tanto no sufro frustración alguna". El niño queda sometido al imperativo de gozar narcisista e inhibido del conocimiento de sus capacidades de imbricación en la cultura (p.203).

No es que Jorge busque emociones fuertes y movimientos agresivos para recibir la atención que necesita, sino que agitarse es también una forma de "no estar". Mutismo de quien cuyo impulso no ha sido am/parado en/por el lenguaje de Otro y no ha padecido el desprendimiento subjetivo, la partición de su ser provocada por la colisión de la palabra en el aparato psíquico (p.144). La cual le permitiría cifrar su necesidad vital mediante símbolos gramaticales; dicho de otro modo, vestir su significante con los significados en el orden de un vínculo social (Lacan, 2008, p.68). "No estar" o "estar ausente", tanto en su imaginación como en "su rabia y su pena", puede ser el modo en que Jorge logra satisfacer su pulsión. El niño obtiene placer inmediato en lo único que puede controlar: gozar de su pensamiento mágico. Objeto incestuoso que lo lleva a mortificar su deseo y destruir lo extraño que le rodea (Freud, 1991, p.118). Impulso desregulado que lo aísla, lo aleja, de los otros y de los medios culturales que provee la escuela.

Parece que la mirada de María tiene el poder de interrumpir el destino natural con el que Jorge tiende a sucumbir bajo la ausencia del Otro de la confianza incondicional. El gesto de la maestra: "no, ahora yo te paro aquí", opera como castración del placer que el niño obtiene en su pulsión (de muerte). La palabra de María suspende el plegarse del niño a su pensamiento mágico (objeto fantasma) con el que suple su ser partido. Gesto que deja en Jorge un vacío disponible para que la energía libidinal -Eros- (p.147) prosiga la búsqueda de ese "algo" simbólico que lo complete -a través de la materialidad del presente, la tarea escolar que está por hacerse, las relaciones con los compañeros de clase, etc.-. La sublimación mediante la ley de la palabra del goce de todo y de cualquier cosa deja el deseo liberado del Yo egológico, susceptible de ser erotizado, para poder dirigirse hacia el otro y lo otro (Lacan, 2015, p.60).

Lo que desea el deseo es ser deseado por el deseo del otro, sentirse amado y amar equivale a entrar en lo humano. O sea, desprenderse de lo animal monstruoso que lo devora todo con un hambre insaciable. Lejos del placer más fácil e instantáneo con el que el niño se consume a sí mismo, la maestra intenta que experimente la vitalidad de la potencia hacia un más allá de su capacidad de acción. Para encender ese deseo de saber y de mundo, la maestra coloca al niño ante su impotencia. La impotencia que lleva en sí el germen de la potencia que enciende la erotización del cuerpo y el conocimiento para actualizarse en acto. Según Giorgio Agamben (2011, p.64): es- 
te carácter ambivalente de la potencia entre "lo que puede" y "lo que no puede" es lo que diferencia, precisamente, al ser humano de los otros seres.

Como viviente de límites -ya sea de hacer o de no hacer, ya sea de ser o de no ser- estamos expuestos al riesgo del error, pero el límite nos permite ejercitar y dominar nuestras facultades. Lo que define el rango de la acción humana es asumir la experiencia de lo que no puede hacerse o no puede serse, incorporar la imposibilidad (que sí significa un padecimiento) y, desde ahí, el tránsito hacia una merma de arrogancia y el despertar de las propias capacidades (p.65).

La pasión por la cultura aguarda como potencia en los niños, dice María: "debajo de su porquería" y fuera de "la pena que los engancha", a ser intrigada por la palabra del otro y así pasar al acto. El encargo del educador es transmitir la acción normativa de lo simbólico que opera mediante el lenguaje. Provocar un trabajo singular de invocación de la cultura que promete sacar la vida del niño de la opresión del placer liberado de responsabilidad. A cambio de una pérdida del instinto acéfalo, la cultura promete el derecho a desear por su cuenta (Recalcati, 2014, p.33). A cambio de una amputación de la naturaleza ilimitada del poder, el niño recibe la energía de un deseo responsable. La imposibilidad de serlo todo y quererlo todo, hace posible la inscripción en la comunidad (Lévinas, 1993, p.100). La limitación de la potencia independiente de nada, sumerge al sujeto en la condición finita de la vida humana.

La ley del lenguaje que representa el educador sirve de corte ante la fuerza bruta que ha extraviado todo sentido del horizonte. La experiencia del límite libera la vida de la cárcel del placer ininterrumpido de la pulsión. El límite aloja al niño en la dimensión herida de la existencia. El aprendizaje de la finitud es encuentro con la propia condición vulnerable (Mèlich, 2015, p.239). La acción de la palabra del otro nos coloca ante lo imposible de nuestra potencia, recordándonos la situación dependiente de nuestra vida. El lenguaje nos expone a la necesidad de ser reconocidos por alguien, inscribe en nuestra conciencia el imperativo ético de hacernos responsable tanto de nuestro deseo como del deseo del otro (Lévinas, 2015, p.190). Porque el sentimiento de vida se alimenta del amor del otro, lo que vivifica la vida es una cierta mortificación de la fantasía de autodeterminación.

La palabra del educador revela el deseo como necesitado de aceptación, arrancándolo de su aislamiento. Estar limitado es asumir la vulneración en que se está. El lenguaje acoge a uno en la casa del prójimo, sirve de cobijo para las heridas (p.191). Aprender la imposibilidad significa vulnerarnos a la necesidad de filiación en una cultura. Frustración de la prepotencia que, con el límite, se convierte en potencia. Del placer de predominar sobre todo y sobre todos, al límite que enfrenta al sujeto con la realidad finita del existir. Existencia quiere decir, en sentido enfático, llamamiento de significación para el otro (p.89). La prepotencia del deseo que se quiere dueño de sí mismo se encuentra con la presencia de un muro, de un dique, que revela su impotencia y, por tanto, descubre la forma humana de la potencia. Dicho de otro modo, el curso de la potencia hacia el acto no puede desatender ni prescindir del otro del lenguaje: su constitución depende de él (Bárcena, 2012, p.196).

La función de la ley de la cultura es la castración simbólica del "gozar sin responder" del otro. Esta ley establece que el deseo de uno -la propia palabra- no puede predominar por sobre el de-seo -la palabra- del otro, sino que debe "hacerse cargo" de él -de ella- (Lacan, 2015, p.378). Cuando el sujeto interioriza la ley como propia y fundacional de su filiación, la transmisión de esta ley anima la prohibición ética de matar -física o semióticamente- al otro (y de matarse a uno mismo). La palabra en el humano establece una separación, entonces, entre el deseo y la tendencia mortífera, abriendo al ser a la relación de responsabilidad por la vida del prójimo ( $\mathrm{y}$ por la suya propia). El límite pone freno a la negación de la vida para generar una cierta afirmación del deseo de vivir. "Porque en el fondo hay una parte de Jorge que no es la agitación y la inquietud lo que quiere". Tal vez, la principal encomienda de un educador sea el gesto ético de dar ganas de vivir, algo así como la transmisión al otro del amor por la vida (Larrosa, 2012, p.26). 


\section{CONSIDERACIONES FINALES}

La experiencia del límite, que a menudo aflige y desespera, llega como experiencia de la propia fragilidad. En ella el vivir se revela como provisional y el propio bagaje como precario. Por eso lo limítrofe es el momento del hilván con lo otro y con el otro. Si el límite puede leerse como zona de vulneración, entonces, éste implica la necesidad del lazo con los demás. Unión que cobija en el contacto con la otredad; otredad que pone al sujeto fuera de lo propio y lo lleva a "ser de otro modo". Estar limitado significa demanda de abrigo y de luz, búsqueda de sentido, no sólo el final de algo sino la transición hacia otros modos de ser y de vincularse con las cosas.

La libertad requiere unas fronteras que protejan a la infancia $-\mathrm{y}$ al mundo- de su propia impulsividad. El límite estructura unos contornos en la organización interna, ofrece regulaciones que el niño subjetiva como conciencia de sí y de lo otro. Frustra el "impulso hacia todo" propio de la naturaleza, separándolo de lo Mismo de sí mismo, y despertando en él el deseo de alteridad. Lo abre hacia el "deseo del otro" que construye, de lo animal, un mundo humano. Esta ligadura con el mundo humano compensa su imposible autarquía. En tanto ser limitado, ser partido, ser simbólico, la palabra del niño necesita de la otra mitad del diálogo y la interpretación de los demás para realizarse.

A la hora de marcar un límite, el niño no necesita muchas palabras sino un adulto que acepte su dolor y lo acompañe en su experiencia. Alguien que no intente desviar su atención o enseñarle, alguien que le deje llorar o protestar sin disuadirle de sus sentimientos o de sus pensamientos. Y es que el niño padece el impasse de una decisión al confrontar el hecho de que su libertad significa "responsabilidad para con el otro". E implica leyes, prohibiciones y reglas que sólo tienen sentido pedagógico si, por otra parte, autorizan a otra cosa o a otro entorno, y si el niño así lo vive. Se limita una pulsión en el niño pero, a la par, se le ofrece un espacio preparado donde pueda materializar su satisfacción de forma segura.

En este sentido, se le presenta una gramática: un juego de lenguaje, un conjunto de símbolos, signos, hábitos, ritos, valores e instituciones que configuran una cultura. Una cultura que limita ciertas formas de interacción de los niños, para reorientar su deseo hacia relaciones de cuidado de sí, de los demás y del mundo. No sólo un cierto orden normativo sino también, y al mismo tiempo, se ha de posibilitar que la criatura desarrolle la facultad ética de interrumpirlo según las necesidades de la situación.

Más que transferir a la criatura una moral sin Otro, el educador responde "en persona" del límite que marca, es "límite viviente". Lo cual quiere decir que sólo mostrándose él mismo "sometido" a lo imposible, podrá vehicular la ley como acotación del goce narcisista. No se puede identificar con la titularidad de la ley puesto que está obligado a perder la soberanía sobre los otros y, por lo tanto, a albergar en sí mismo el deseo de relación. Asumir la prohibición de predominar sobre los demás y admitir la propia fragilidad ante la contingencia de la vida, habilita al educador a otorgar a los otros la cultura como fundamento del deseo.

\section{REFERENCIAS}

Adorno, T.(2018). Notas sobre literatura. Madrid: Akal.

Agamben, G. (2019). La potencia del pensamiento. Buenos Aires: Adriana Hidalgo.

Agamben, G. (2011). Desnuder. Buenos Aires: Adriana Hidalgo.

Arbiol, C. (2018). Elementos para una pedagogía de la alteridad en la práctica de educadoras sociales. Teoría de la educación, 30 (2), 109-129.

Ayala, R. (2018). La relación pedagógica: en las fuentes de la experiencia educativa con van Manen. Revista Complutense de Educación, 29 (1), 27-41. 
Ávalos, M. L., Palos, M. U. \& Miranda, R. B. (coord.) (2019). Prácticas y reflexiones sobre la educación contemporánea. México: Nómada.

Bárcena, F. (2004). El delirio de las palabras. Barcelona: Herder.

Bárcena, F. (2012). El aprendiz eterno. Buenos Aires: Miño y Dávila.

Bárcena, F. \& Mèlich, J-C. (2014). La educación como acontecimiento ético. Buenos Aires: Miño y Dávila.

Biesta, G. (2017). El bello riesgo de educar. Madrid: SM.

Brailovsky, D. (2019). Pedagogía (entre paréntesis). Buenos Aires: Noveduc.

Contreras, J. \& Pérez de Lara, N. (Eds.). (2010). Investigar la experiencia educativa. Madrid: Morata.

Contreras, J. (coord.) (2016). Tensiones fructiferas. Barcelona: Octaedro.

Contreras, J. (coord.) (2017). Enseñar tejiendo relaciones. Madrid: Morata.

Clandinin, J. (2016). Engaging in narrative inquiries with children and youth. New York: Routledge.

Clandinin, J. (2018). The Relational Ethics of Narrative Inquiry. New York: Routledge.

Deleuze, G.\& Guattari, F. (2013). ¿Qué es la filosofía?. Barcelona: Anagrama.

Dewey, J. (1998). Democracia y Educación. Madrid: Morata.

Foucault, M. (2018). ¿Qué es la crítica? Buenos Aires: Siglo XXI.

Freud, S. (1991). Nuevas conferencias de introducción al psicoanálisis. Buenos Aires: Amorrortu.

Freud, S. (1992). Más allá del principio del placer: Psicología de las masas y análisis del yo y otras obras. Buenos Aires: Amorrortu.

Gadamer, H-G. (1977). Verdad y método I. Salamanca: Sígueme.

Han, B-Ch. (2014). La agonía del Eros. Barcelona: Herder.

Kohan, W. (2019). Paulo Freire mais do que nunca: Uma biografia filosófica. Belo Horizonte: Vestígio.

Lacan, J. (2007). La ética del psicoanálisis. Buenos Aires: Paidós.

Lacan, J. (2008). El Yo en la teoría de Freud. Buenos Aires: Paidós.

Lacan, J. (2010). Los cuatro conceptos fundamentales del psicoanálisis. Buenos Aires: Paidós.

Lacan, J. (2013). Escritos I. Madrid: Biblioteca Nueva.

Lacan, J. (2015). El deseo y su interpretación. Buenos Aires: Paidós.

Larrosa, J. (2012) Algunas citas sobre la educación y las ganas de vivir. En Bárcena, F. (2012). El aprendiz eterno. Buenos Aires: Miño y Dávila.

Larrosa, J. (2017). Pedagogía profana. Buenos Aires: Miño y Dávila.

Lévinas, E. (1987). De otro modo que ser, o más allá de la esencia. Salamanca: Sígueme.

Lévinas, E. (1993). El tiempo y el otro. Madrid: Paidós.

Lévinas, E. (2015). Ética e infinito. Madrid: Antonio Machado.

Lledó, E. (2005). Elogio de la infelicidad. Madrid: Cuatro.

Lukács, G. (2016). El alma y las formas. Barcelona: Grijalbo.

Meirieu, P. (2015). Frankenstein educador. Barcelona: Laertes.

Meirieu, P. (2016). Recuperar la pedagogía. Buenos Aires: Paidós.

Mèlich, J-C. (2014). La condición vulnerable. Ars Brevis, 20, 313-331.

Mèlich, J-C. (2015). Ética de la compasión. Barcelona: Herder.

Meneses, J., Rodríguez, D. \& Valero, S. (2019). Investigación educativa: Una competencia profesional para la intervención. Barcelona. UOC. 
Najmanovich, D. (2019). Complejidades del saber. Buenos Aires: Noveduc.

Pennac, D. (2008). Mal de escuela. Barcelona: Debolsillo.

Recalcati, M. (2014). El complejo de Telémaco. Barcelona: Anagrama.

Recalcati, M. (2016). La hora de clase. Barcelona: Anagrama.

Sierra, E. \& Blanco, N. (2017). El Aprendizaje de la Escucha en la Investigación Educativa. Qualitative Research in Education, 6 (3), 303-326.

Sierra, J. E. (2019). Entre nuestras urgencias y sus deseos, la escucha. Márgenes, Revista de Educación de la Universidad de Málaga, 0 (0), 119-122.

Skliar, C. (2017). Pedagogías de las diferencias. Buenos Aires: Noveduc.

Van Manen, M. (2003). Investigación educativa y experiencia vivida. Barcelona: Idea Books.

Van Manen, M. (2015). El tacto en la enseñanza. Barcelona: Paidós.

Wild, R.(2015). Libertad y límites. Amor y respeto. Barcelona: Herder.

Submetido: $18 / 03 / 2019$

Aprovado: $11 / 10 / 2019$ 